\title{
Fluorinated Thiophene Units Improve Photovoltaic Device Performance of Donor-Acceptor Copolymers
}

\author{
Qianqian Zhang, ${ }^{\dagger} \odot$ Liang Yan, ${ }^{\dagger}$ Xuechen Jiao, ${ }^{\ddagger}$ Zhengxing Peng, ${ }^{\ddagger}$ Shubin Liu, ${ }^{\S}$ Jeromy James Rech, ${ }^{\dagger}$
}

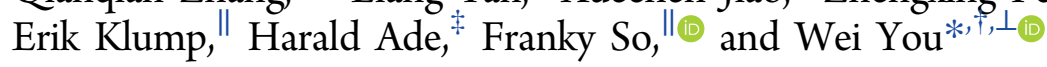

${ }^{\dagger}$ Department of Chemistry, University of North Carolina at Chapel Hill, Chapel Hill, North Carolina 27599-3290, United States

${ }^{\ddagger}$ Department of Physics and ORaCEL, North Carolina State University, Raleigh, North Carolina 27695, United States

${ }^{\S}$ Research Computing Center, University of North Carolina at Chapel Hill, Chapel Hill, North Carolina 27599-3420, United States

"Department of Materials Science and Engineering, North Carolina State University, Raleigh, North Carolina 27606, United States

${ }^{\perp}$ Department of Applied Physical Sciences, University of North Carolina, Chapel Hill, North Carolina 27599-3216, United States

ABSTRACT: Fluorinated conjugated polymers leading to enhanced photovoltaic device performance has been widely observed in a variety of donoracceptor copolymers; however, almost all these polymers have fluorine substituents on the acceptor unit. Building upon our previously reported PBnDT-FTAZ, a fluorinated donor-acceptor conjugated polymer with impressive device performance, we set this study to explore the effect of adding the fluorine substituents onto the flanking thiophene units between the donor unit (BnDT) and the acceptor unit (TAZ). We developed new synthetic approaches to control the position of the fluorination $\left(3^{\prime}\right.$ or $\left.4^{\prime}\right)$ on the thiophene unit, and synthesized four additional PBnDT-TAZ polymers incorporating the fluorine-substituted-thiophene (FT) units, 3'-FT-HTAZ, 4'FT-HTAZ, 3'-FT-FTAZ, and 4'-FT-FTAZ. We discover that relocating the fluorine substituents from the acceptor to the flanking thiophene units have a

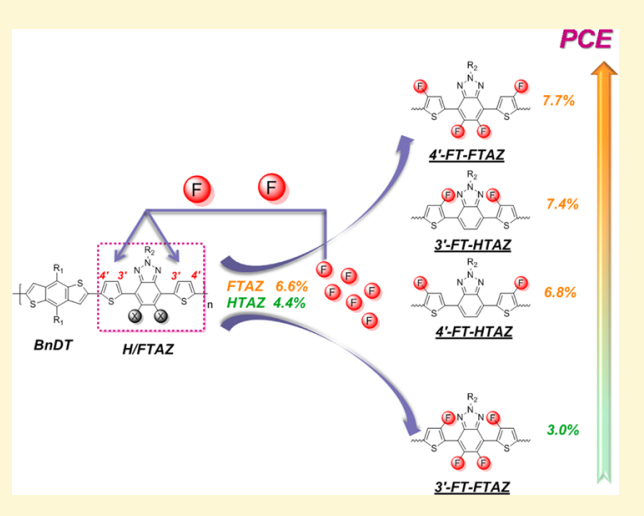
negligible impact on the device characteristics (short circuit current, open circuit voltage, and fill factor) when comparing $4^{\prime}$-FTHTAZ with the original FTAZ. Combining these two fluorination approaches together, $4^{\prime}$-FT-FTAZ shows even higher device performance than FTAZ (7.7\% vs 6.6\%) with active layers over $200 \mathrm{~nm}$ in thickness. Furthermore, high values of fill factor $70 \%$ are all achieved for photovoltaic devices based on $3^{\prime}$-FT-HTAZ, 4'-FT-HTAZ, or 4'-FT-FTAZ, ascribed to the observed high hole mobilities (over $1 \times 10^{-3} \mathrm{~cm}^{2} /(\mathrm{V} \mathrm{s})$ ) in these devices. Our study offers a new approach to utilize the fluorinated thiophene units in developing new conjugated polymers to further improve the device performance of polymer solar cells.

\section{INTRODUCTION}

Further understanding the structure-property relationship of conjugated polymers and small molecules for solar cells has been driving this research field forward with newer and better materials. ${ }^{1,2}$ These novel materials, aided by device engineering and morphology optimization, have improved the power conversion efficiency of such solar cells to an impressive level of over $12 \%$ for both single junction ${ }^{3}$ and tandem cells. ${ }^{4}$ Among various molecular design strategies for these novel materials, fluorination is a unique one. ${ }^{1,2,5}$ The $\sigma$-withdrawing (yet $\pi$ donating) ability of fluorine substituents lowers the energy levels of conjugated polymers and small molecules, which can afford a higher open circuit voltage $\left(V_{o c}\right)$ of photovoltaics devices based on the fluorinated material than that of the nonfluorinated counterpart. ${ }^{6}$ Furthermore, the inter/intramolecular interactions exerted by these fluorine substituents (e.g., F $\cdots H$, F $\cdots S, F \cdots \pi$ ) can have a considerable effect on the conjugated backbone planarity and packing/stacking of these conjugated materials in the solid state. ${ }^{7,8}$ These features can lead to a higher short circuit current $\left(J_{\text {sc }}\right)$ and/or a higher fill factor (FF) of related photovoltaic devices. ${ }^{9}$

Given the electronic nature of fluorine (e.g., $\sigma$-withdrawing), vast majority of the works on fluorinating donor-acceptor (DA) conjugated polymers have been focused on the fluorination of the acceptor units, such as benzothiadiazole (BT), ${ }^{10,11}$ benzotriazole (TAZ), ${ }^{12}$ isoindigo, ${ }^{13}$ and quinoxaline, ${ }^{14}$ all of which are listed in Chart 1 . While fluorinating the acceptor (i.e., "A") units has been very successful, leading to an appreciable efficiency increase of the photovoltaic device based on these fluorine-substituted polymers, the results of polymers having the fluorinated donor (i.e., "D") units have been mixed. For example, Son et al. and Carsten et al. discovered that directly attaching the fluorine substituents to the benzodithiophene $(\mathrm{BnDT})$ in the PTB conjugated polymer was detrimental to the device performance. ${ }^{15,16}$ Interestingly, if the fluorine is

Received: April 26, 2017

Revised: June 30, 2017

Published: July 3, 2017 
Chart 1. Examples of Fluorine-Substituted Structural Units, Highlighting the Position of Fluorination

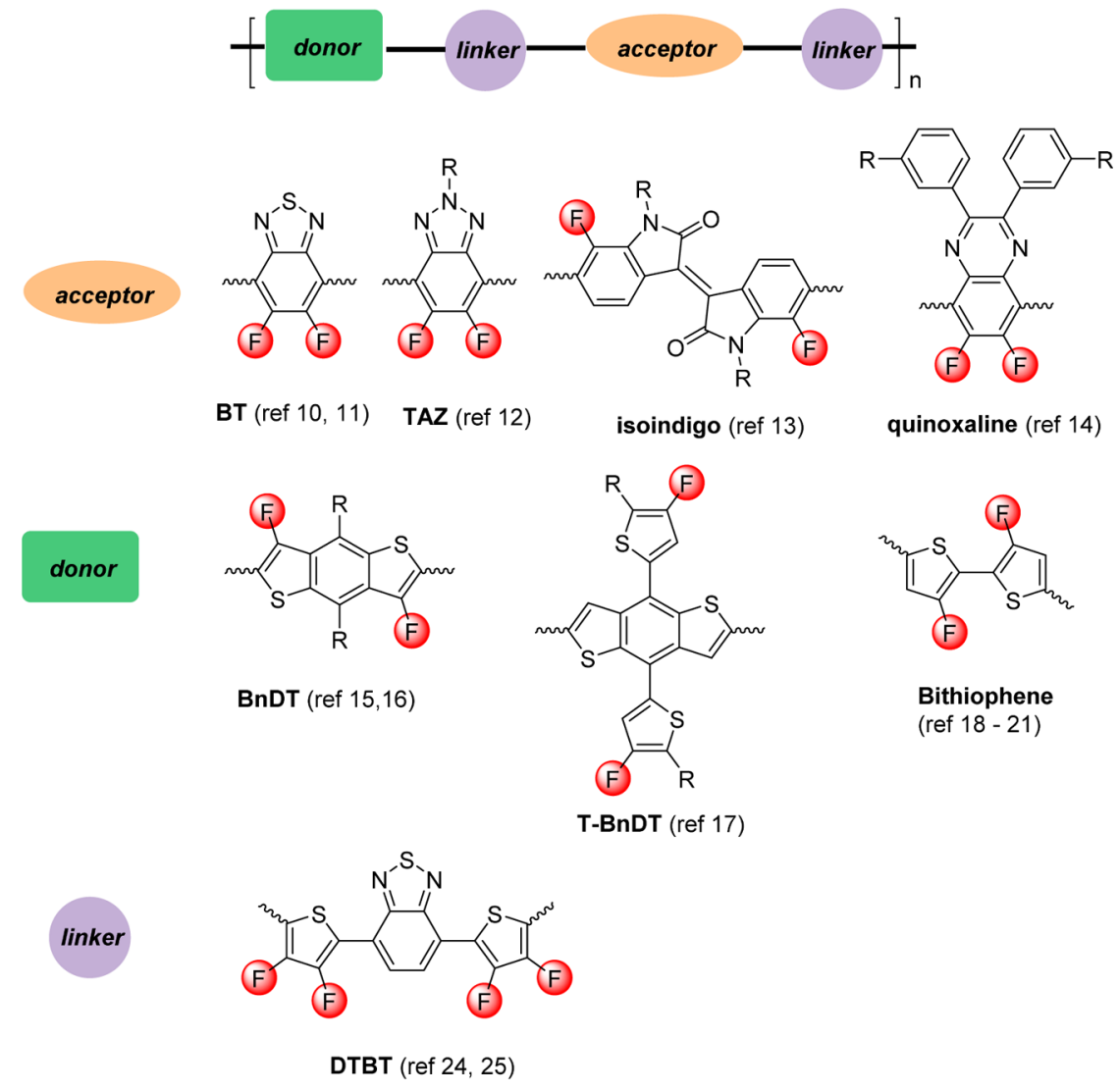

relocated to the thienyl-a conjugated side chain attached to $\mathrm{BnDT}$ in this case, Zhang et al. found that such modified PTB analogs can offer a significantly higher $V_{\text {oc }}$ moderately improved $J_{\text {sc }}$ and $\mathrm{FF}$ in their photovoltaic devices than the nonfluorinated counterpart. ${ }^{17}$ More recently, 3,3'-difluoro-2,2'bithiophene emerged as a successful fluorinated donor unit in improving efficiency of such conjugated polymers based solar cells. ${ }^{18-21}$ However, when Kawashima et al. added two more fluorine substituents to the fluorinated bithiophene, the tetrafluorinated thiophene based polymer only showed significantly reduced $J_{\text {sc }}$ (yet a higher $V_{\text {oc }}$ ) in its photovoltaic device than the difluorinated or unfluorinated counterparts. ${ }^{20}$

In addition to the $\mathrm{D}$ and $\mathrm{A}$ units, conjugated linkers that link $\mathrm{D}$ and $\mathrm{A}$ units often play important roles in affecting the properties of conjugated polymers and the device characteristics of the related solar cells. ${ }^{22,23}$ Interestingly, these conjugated linkers are rarely considered for fluorination. One such example has been documented by the Heeney group. ${ }^{24,25}$ In their studies, Fei et al. added a difluorinated thiophene unit in between the dithienogermole (D) and the benzothiadiazole (A), and the fluorinated polymer showed much higher device efficiency than the nonfluorinated counterpart, mainly due to a much increased $J_{\text {sc }}{ }^{24}$ Furthermore, when Liu et al. used this difluorinated thiophene to copolymerize with thieno[3,4c]pyrrole-4,6-dione (i.e., TPD, an acceptor unit), as-synthesized polymer can be used as a polymer acceptor to pair with a low band gap polymer to reach decent device efficiency. ${ }^{26}$

As one of the first groups in discovering the peculiar " $F$ effect" (i.e., fluorinated polymer leading to enhanced device performance), ${ }^{9,10,12,27}$ we have a keen interest to further explore this interesting behavior. For example, in our earlier

work, we revealed that adding fluorine substituents to the benzotriazole unit in the $\mathrm{D}-\mathrm{A}$ polymer (i.e., from $\mathrm{PBnDT}$ HTAZ to PBnDT-FTAZ) can increase the hole mobility in the related bulk heterojunction $(\mathrm{BHJ})$ device by one order of magnitude, which directly accounts for the much improved FF of the PBnDT-FTAZ based BHJ device. ${ }^{9}$ In our current study, inspired by the recent success on employing the fluorinated bithiophene and the difluorinated thiophene, we decided to explore the effect of fluorination of these two flanking thiophene units between the BnDT (D) and TAZ (A) units. Since each flanking thiophene has two hydrogen atoms $\left(3^{\prime}\right.$ and $\left.4^{\prime}\right)$ that can be substituted with fluorine atoms, together with the $m-\mathrm{H} / \mathrm{FTAZ}$ units, we chose to synthesize four new fluorinated BnDT-TAZ based polymers (Chart 2). These four additional fluorinated polymers constitute a series of structurally closely related polymers to further improve our understanding of the impact of fluorination. For conciseness yet clarity, we will use HTAZ, FTAZ, 3'-FT-HTAZ, 4'-FT-HTAZ, $3^{\prime}$-FT-FTAZ, and $4^{\prime}$-FT-FTAZ to represent the polymers in the following discussion, while $m$-HTAZ, $m$-FTAZ, $m$-3'-FTHTAZ, $m$-4'-FT-HTAZ, $m$-3'-FT-FTAZ, and $m$ - $4^{\prime}$-FT-FTAZ are used to indicate the corresponding monomers. Specifically, 3 -FT-HTAZ and 4'-FT-HTAZ are isomeric to the original FTAZ polymer. More importantly, having these fluorinated thiophenes allows us to have access to the tetrafluorinated polymer, 3'-FT-FTAZ and 4'-FT-FTAZ, which are also isomeric to each other. Together with previously studied PBnDT-HTAZ and PBnDT-FTAZ polymers, this set of six polymers offer a comprehensive system to allow us to probe the "F effect", with a focus on both the number $(0,2,4)$ and the position of the fluorination. 
Chart 2. Series of Fluorinated PBnDT-TAZ Polymers, Highlighting the Number and the Position of Fluorination
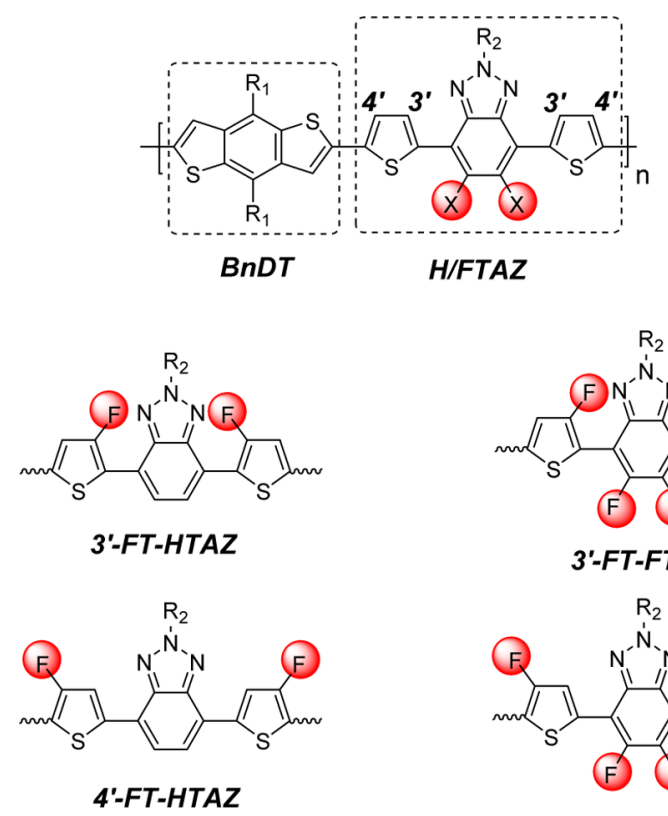

Interestingly, our results show that relocating the two fluorine substituents from the fluorinated benzotriazole unit to the two flanking thienyls does not negatively impact the device performance. While $4^{\prime}$-FT-HTAZ based BHJ device offers similar device characteristics (e.g., $J_{\mathrm{sc}} V_{\mathrm{oC}}$ and FF) to those of FTAZ based one, the 3'-FT-HTAZ presents even higher device efficiency than that of FTAZ based one $(7.4 \%$ vs $6.6 \%$ ), mainly due to the much improved $V_{\text {oc }}$. However, with additional two fluorine substituents on the central benzotriazole unit, that is, converting $3^{\prime}$-FT-HTAZ to $3^{\prime}$-FT-FTAZ, this tetra-fluorinated polymer only shows an increased band gap and a reduced $J_{\mathrm{sc}}$ value in its device, largely due to the steric hindrance from adjacent fluorine substituents. When such steric hindrance is removed in the case of $4^{\prime}$-FT-FTAZ, we are delighted to discover that this tetra-fluorinated polymer ( $4^{\prime}$-FTFTAZ) based BHJ cells can not only maintain the high $J_{\text {sc }}$ and high FF as FTAZ based devices do, but also achieve noticeably increased $V_{\text {oc }}$. Thus, an overall efficiency of $7.7 \%$ is obtained for $4^{\prime}$-FT-FTAZ based device, which is the highest in the studied set of six polymers. Our results clearly demonstrate that adding fluorine substituents to these bridging thiophene units, if judiciously designed, can be a very effective design strategy to further enhance the efficiency of related $\mathrm{BHJ}$ solar cells.

\section{RESULTS AND DISCUSSION}

2.1. Design and Synthesis. The key to the synthesis of these four new fluorinated PBnDT-TAZ polymers is to control the fluorination position in these two flanking thienyl units in regard to the central benzotriazole, that is, achieving the synthesis of monomers $m-3^{\prime} \mathrm{FT}-(\mathrm{H} / \mathrm{F}) \mathrm{TAZ}$ and $m-4^{\prime} \mathrm{FT}-(\mathrm{H} /$ F)TAZ in Scheme 1. We chose Stille coupling to construct these symmetrical monomers from monofluorinated thiophene (FT) and (fluorinated) benzotriazole, which would require the synthesis of two isomeric monofluorinated thiophene units with the properly positioned trimethyl tin group (i.e., 5 and 8 in Scheme 1). To maximize the synthetic efficiency, a divergent route was designed, with the common precursor 3 as the point of divergence toward 5 and 8 . Specifically, the $2^{\prime}$ and $5^{\prime}$ positions of 3-bromothiophene (1) were first protected with trimethylsilyl (TMS) groups to render 2, which was then treated with $n$-butyllithium and underwent electrophilic fluorination with $\mathrm{N}$-fluorobenzenesulfonimide (NFSI) to offer 3 (Scheme 2). ${ }^{28}$ We noticed that this fluorination reaction can produce a significant amount of byproduct (14). To resolve the chemical structure of 14, we applied ${ }^{1} \mathrm{H}$ NMR (Figure S17), ${ }^{13} \mathrm{C}$ NMR (Figure S17) and mass spectrometry to characterize 14 and came up a few plausible chemical structures. The exact chemical structure was finally confirmed by single crystal X-ray

Scheme 1. Synthesis of the Monomers Containing the Fluorinated Thiophene Units

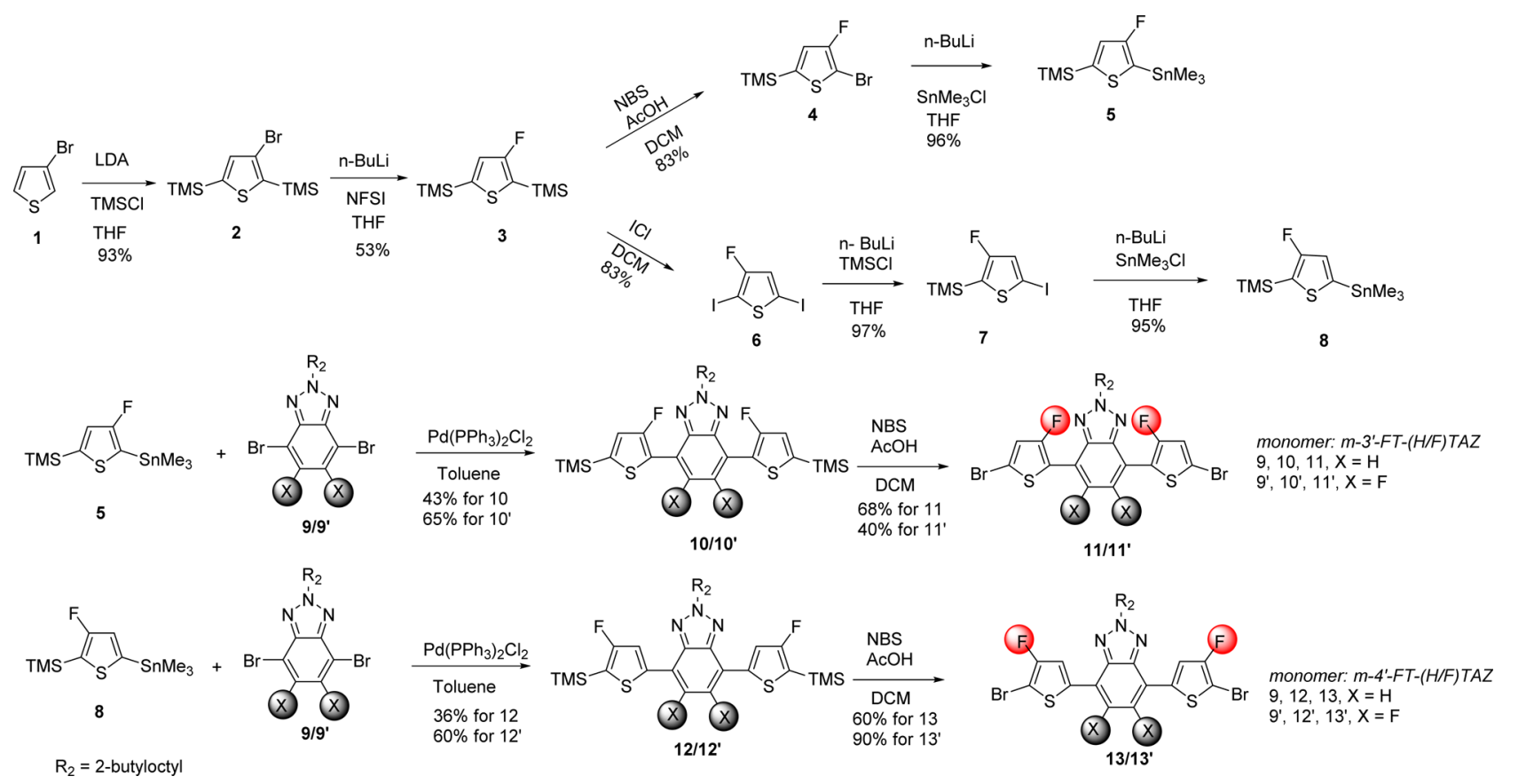


Scheme 2. Synthesis of the Common Precursor (3) and the Byproduct (14)
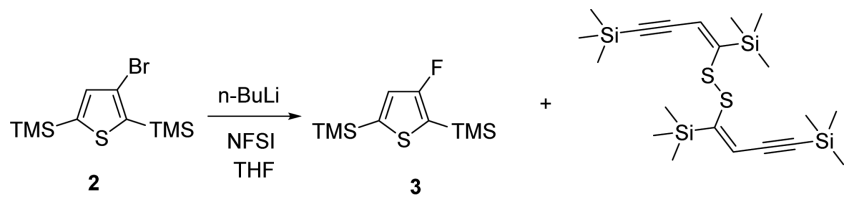

14

characterization (Figure S1). We believed this byproduct (14) was formed as a result of ring opening reactions of thiophene units (Scheme 2). ${ }^{29}$ Details on the proposed mechanism for the formation of this byproduct can be found in Supporting Information (SI). This issue was alleviated by adding the required amount of $n$-butyllithium and NFSI in several portions, which significantly improved the yield of 3 from $10 \%$ (if added in one portion) to $50 \%$ (if added in several portions). Since the position close to the fluorine atom on the substituted thiophene (3) is more reactive, a selective bromination of the $2^{\prime}$ position of 3 , followed by lithiumhalogen exchange and stannylation, offered the desired precursor 5, ready for the next Stille coupling and bromination to prepare the monomer, $m-3^{\prime} \mathrm{FT}-(\mathrm{H} / \mathrm{F}) \mathrm{TAZ}$. On the other hand, the synthesis of precursor $\mathbf{8}$, the isomer to 5 , started with the iodination of 3 to reach an intermediate 6 . Again, taking advantage of the more reactive $2^{\prime}$ position of 6 , we selectively anchored a TMS protecting group at the $2^{\prime}$ position, leaving $5^{\prime}$ position for lithium-halogen exchange and stannylation to successfully synthesize 8. This key precursor (8) underwent standard Stille coupling with (fluorinated) benzotriazole, followed by bromination, to offer the other monomers, $m$ $4^{\prime} \mathrm{FT}-(\mathrm{H} / \mathrm{F}) \mathrm{TAZ}$. The positions of fluorine in $m-3^{\prime}-\mathrm{FT}-\mathrm{HTAZ}$ and $m-4$-FT-HTAZ were well explained by comparing the ${ }^{1} \mathrm{H}$ NMR spectra of these two monomers with that of $m$-HTAZ monomer (with/without bromine groups) and further confirmed by proton NOESY spectra (Figures S2-S4). In addition, the strong ${ }^{19} \mathrm{~F}-{ }^{19} \mathrm{~F}$ coupling of the $m$-3'-FT-FTAZ indicated that the fluorine substituents on two flanking thienyls are close to the fluorine on the central FTAZ unit (Figure S26). These NMR characterizations clearly indicate the successful control of fluorination position on these flanking thienyl units through our synthetic approach (Scheme 1). More reaction details were included in SI.

All monomers were subjected to the Stille-coupling-based polymerization according to Scheme 3, following the polymerization condition previously optimized to reach a desirable molecular weight. ${ }^{30}$ However, given the vicinity of fluorine to the bromine on the flanking thienyl units in the case of $4^{\prime}$-FT monomers, the reactivity of these two monomers is affected.
We noticed that, for monomer $m-4^{\prime}$-FT-HTAZ, extended polymerization time and reduced ligand:catalyst ratio (3:1 of $\mathrm{P}(o \text {-tol })_{3}$ to $\mathrm{Pd}$, instead of $\left.4: 1\right)$ were required to reach a sufficiently high molecular weight of $32 \mathrm{~kg} / \mathrm{mol}$. As for $4^{\prime}$-FTFTAZ, extended polymerization time and increased catalyst loading vs monomers (from $2 \%$ to $4 \%$ ) were required to get a sufficiently high molecular weight of $21 \mathrm{~kg} / \mathrm{mol}$. Nevertheless, the molecular weight values of those two $4^{\prime}$-FT polymers are still relatively low when compared with other polymers in this study (Table 1), likely due to the low solubility of these two 4'FT polymers. Lastly, we were able to further increase the molecular weights of these two 4 '-FT polymers by adding DMF as a cosolvent for polymerization; ${ }^{31}$ however, the increased molecular weight further decreased the solubility of the polymer, without any appreciable improvement on efficiencies of related BHJ devices (Tables S7 and S8). The molecular weights of the polymers were measured by high temperature gel permeation chromatography (GPC), and results were summarized in Table 1. More polymerization details were included in SI.

2.2. Computation and Modeling. We performed density functional theory (DFT) calculations at the DFT B3LYP/6$311+G(d)$ level of theory ${ }^{32-34}$ on one repeating unit of all six polymers in this study, focusing on the twisting angles between adjacent units and the energy levels of these polymers. To reduce the computation time yet still maintaining the branched nature of the side chains, isopropyl chains were used to replace the long and branched side chains in the repeating unit. Figure 1 presents the most stable conformations for these six different yet structurally tightly related repeating units (i.e., the only difference being the number and the position of fluorine substituents), from which we calculated the energy levels and band gaps. The related results are summarized in Table 1. Furthermore, the computed electron distribution at the ground and excited states of one repeating unit of all six polymers is provided in Figure S8.

Overall, the fluorination positions of these two flanking thienyl units has a strong impact on the most stable conformation and the twisting angles between adjacent aromatic units (Figure 1); in contrast, adding two fluorine substituents to the central benzotriazole only introduce little perturbation to the conformation and the twisting angle (e.g., comparing HTAZ and FTAZ in Figure 1). Notably, adding a fluorine atom to the $3^{\prime}$ position of the thienyl units not only switches the relative orientation of the central benzotriazole (TAZ) unit (in regard to the flanking thienyls) in the most stable conformation but also slightly increases the twisting angles between the $\mathrm{BnDT}$ unit and the adjacent thienyl units (i.e., comparing 3'-FT-HTAZ and HTAZ). We ascribe such

Scheme 3. Stille-Coupling-Based Polymerizations to Create the Set of Six Polymers

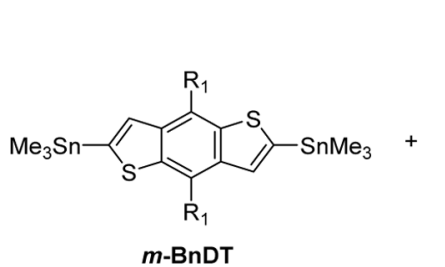

$\mathrm{R}_{1}=$ 3-butylnonyl; $\mathrm{R}_{2}=2$-butyloctyl

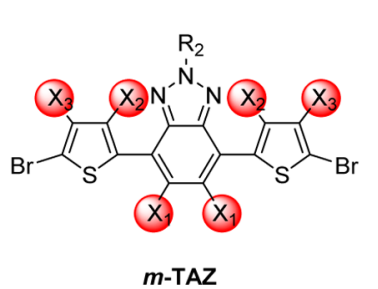

$m-$ TAZ

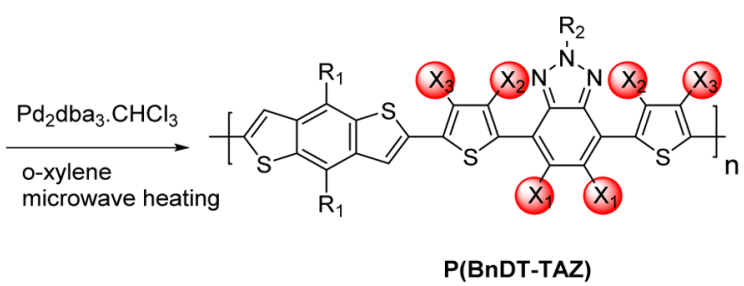

HTAZ: $\mathrm{X}_{1}=\mathrm{X}_{2}=\mathrm{X}_{3}=\mathrm{H}$; FTAZ: $\mathrm{X}_{1}=\mathrm{F}, \mathrm{X}_{2}=\mathrm{X}_{3}=\mathrm{H}$

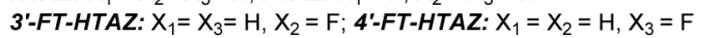

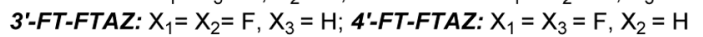


Table 1. Molecular Weights, Calculated and Measured Energy Levels, and Band Gaps of All Six Polymers

\begin{tabular}{lccccccc}
\multicolumn{1}{c}{ polymers } & $M_{\mathrm{n}}(\mathrm{kg} / \mathrm{mol})$ & $\oplus\left(M_{\mathrm{w}} / M_{\mathrm{n}}\right)$ & $\mathrm{HOMO}^{a}(\mathrm{cal}, \mathrm{eV})$ & $\mathrm{LUMO}^{a}(\mathrm{cal}, \mathrm{eV})$ & band gap $^{a}(\mathrm{cal}, \mathrm{eV})$ & $\mathrm{HOMO}^{b}(\mathrm{CV}, \mathrm{eV})$ & band Gap $^{c}\left(\mathrm{opt}^{\mathrm{eV}}\right)$ \\
\hline HTAZ & 70 & 3.4 & -5.17 & -2.44 & 2.74 & -5.47 & 1.98 \\
FTAZ & 55 & 1.9 & -5.28 & -2.54 & 2.73 & -5.56 & 2.00 \\
3'-FT-HTAZ $^{\prime}$ & 80 & 1.9 & -5.26 & -2.48 & 2.78 & -5.64 & 1.98 \\
4'-FT-HTAZ $^{\prime}$ & 32 & 2.7 & -5.28 & -2.67 & 2.61 & -5.59 & 1.87 \\
3'-FT-FTAZ $^{\prime}$ & 101 & 1.9 & -5.50 & -2.43 & 3.06 & -5.87 & 2.23 \\
4'-FT-FTAZ $^{\prime}$ & 21 & 2.5 & -5.36 & -2.82 & 2.54 & -5.64 & 1.90
\end{tabular}

${ }^{a}$ Calculated by DFT. ${ }^{b}$ Measured by cyclic voltammetry. ${ }^{c}$ Band gap estimated from the onset of UV-vis absorption of polymer films.

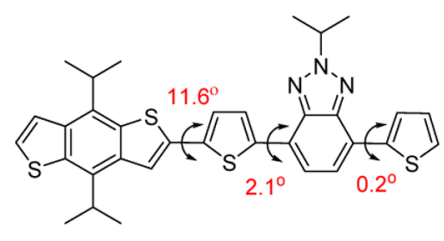

BnDT-HTAZ

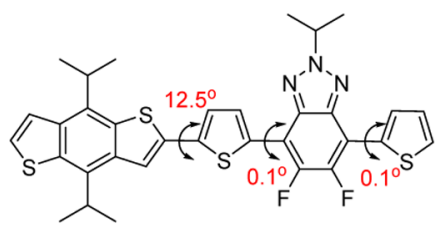

BnDT-FTAZ

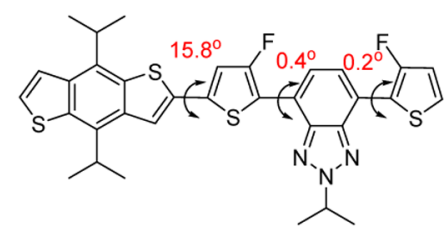

BnDT-3'-FT-HTAZ

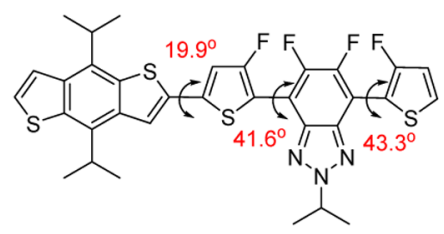

BnDT-3'-FT-FTAZ

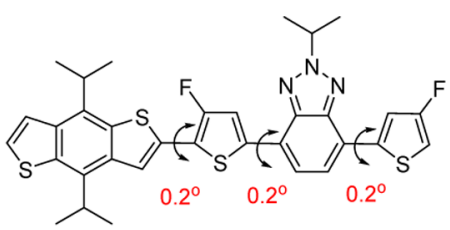

BnDT-4'-FT-HTAZ

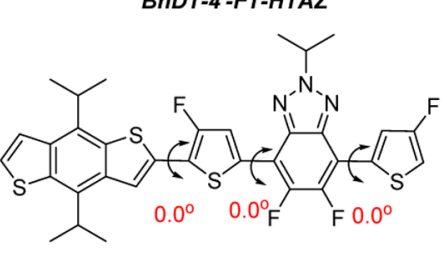

BnDT-4'-FT-FTAZ

Figure 1. Computed twisting angles of the most stable conformation of one repeating unit.
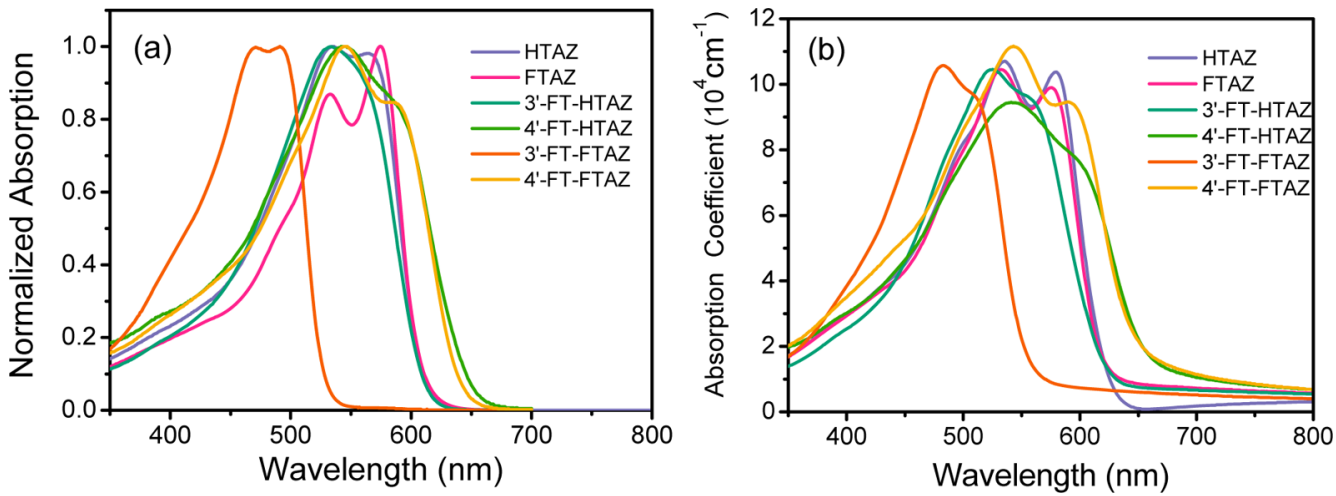

Figure 2. Normalized UV-vis spectra of all six polymers (a) in their solutions in trichlorobenzene $(\mathrm{TCB})$ at $10^{-2} \mathrm{mg} / \mathrm{mL}$ and $(\mathrm{b})$ as thin films cast from their TCB-based solutions.

changes to the relative strength of different hydrogen-bonding interactions (e.g., $\mathrm{N} \cdots \mathrm{H}$ vs $\mathrm{F} \cdots \mathrm{H}$ ), the $\mathrm{S} \cdots \mathrm{F}$ interaction, electrostatic interactions and steric interactions. ${ }^{25,35}$ For example, the newly emerged $\mathrm{F}$ (on $\left.3^{\prime}-\mathrm{FT}\right) \cdots \mathrm{H}$ (on TAZ) hydrogen bonding eliminates the $\mathrm{N}$ (on TAZ) $\cdots \mathrm{H}$ (on thiophenyl) hydrogen bonding and results in flipping the central TAZ unit in $3^{\prime}$-FT-HTAZ. However, with two additional fluorine substituents on benzotriazole in the case of 3 -FT-FTAZ, the repulsive electrostatic interactions of F (on $3^{\prime}$-FT) $\cdots \mathrm{F}$ (on fluorinated TAZ) for the conformer as shown in Figure 1, and $\mathrm{F}$ (on $3^{\prime}-\mathrm{FT}$ ) $\cdots \mathrm{N}$ (on fluorinated TAZ) for the other conformer where the fluorinated TAZ is flipped, significantly increase the dihedral angle between $3^{\prime}$-FT and the fluorinated TAZ. On the other hand, switching the fluorination from the $3^{\prime}$ position to the $4^{\prime}$ position not only allows to maintain the original conformation of the thienyl-
TAZ-thienyl, also further decreases the dihedral angle between the BnDT unit and the thienyl unit likely due to the newly added $S$ (on BnDT) $\cdots \mathrm{F}$ (on $4^{\prime}-\mathrm{FT}$ ) interaction. All these features lead to almost perfectly planar backbones for $4^{\prime}$-FTHTAZ and $4^{\prime}$-FT-FTAZ, which explains the smaller band gaps of these two $4^{\prime}$-FT polymers calculated by DFT (Table 1 ).

2.3. Optical and Electrochemical Properties. After obtaining all six polymers in this study, we next investigated how the position and number of fluorine substitutions would affect the optical properties of these polymers. As shown in Figure $2 b$, the absorption edge of $3^{\prime}$-FT-HTAZ is essentially identical to those of FTAZ and HTAZ, indicating a similar band gap of $\sim 2.0 \mathrm{eV}$ for these three polymers (Table 1). This experimental result matches very well with the similar planarity for these three polymers (Figure 1). In contrast, the severe steric hindrance observed in the 3 '-FT-FTAZ (Figure 1) results 

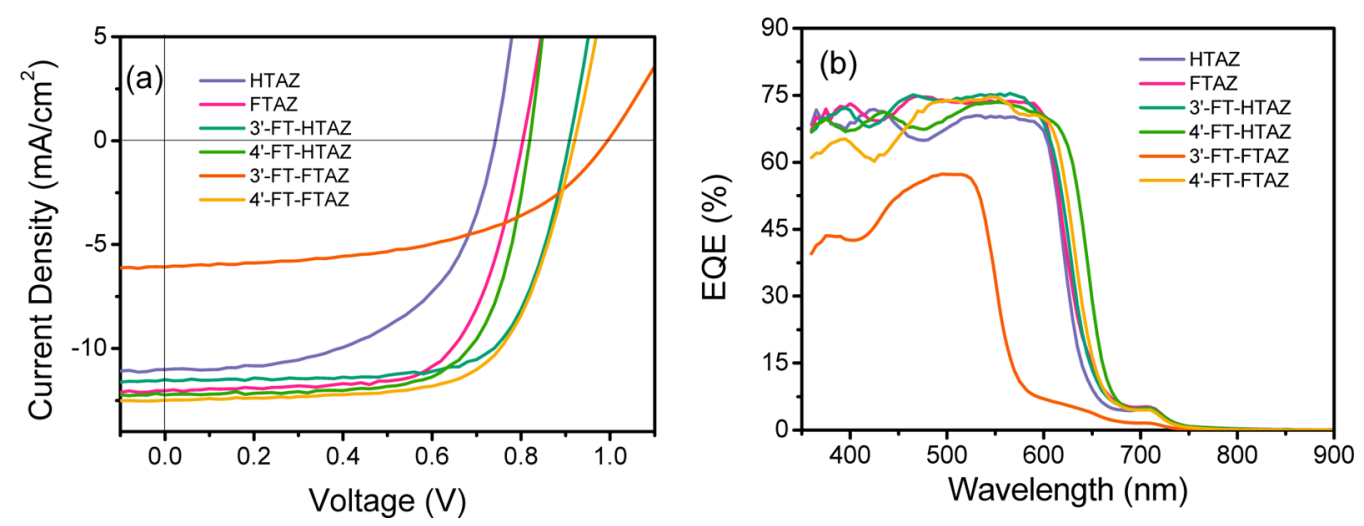

Figure 3. (a) $J-V$ curves and (b) EQE spectra of $\mathrm{BHJ}$ solar cells based on all six polymers.

Table 2. Photovoltaic Parameters of Polymer Solar Cells

\begin{tabular}{|c|c|c|c|c|c|c|c|}
\hline polymer & solvent & thickness $(\mathrm{nm})$ & $J_{\mathrm{sc}}\left(\mathrm{mA} / \mathrm{cm}^{2}\right)$ & $V_{\mathrm{oc}}(\mathrm{V})$ & FF (\%) & efficiency (\%) & mobility $\left(\times 10^{-3} \mathrm{~cm}^{2} / \mathrm{V} \cdot \mathrm{s}\right)^{a}$ \\
\hline HTAZ & TCB & 249 & $11.10 \pm 0.25$ & $0.741 \pm 0.001$ & $53.3 \pm 1.3$ & $4.39 \pm 0.17$ & 0.17 \\
\hline FTAZ & $\mathrm{TCB}$ & 308 & $12.02 \pm 0.25$ & $0.805 \pm 0.001$ & $68.0 \pm 1.0$ & $6.58 \pm 0.21$ & 1.20 \\
\hline 3'-FT-HTAZ & $\mathrm{CB}+3 \% \mathrm{DIO}$ & 272 & $11.72 \pm 0.15$ & $0.909 \pm 0.002$ & $69.6 \pm 1.0$ & $7.42 \pm 0.14$ & 4.62 \\
\hline $4^{\prime}$-FT-HTAZ & ТСВ & 205 & $12.02 \pm 0.58$ & $0.820 \pm 0.001$ & $69.3 \pm 0.9$ & $6.82 \pm 0.32$ & 1.26 \\
\hline 3'-FT-FTAZ & $\mathrm{CB}+3 \% \mathrm{DIO}$ & 154 & $6.01 \pm 0.27$ & $0.991 \pm 0.006$ & $51.2 \pm 0.8$ & $3.05 \pm 0.16$ & 0.12 \\
\hline 4'-FT-FTAZ & $\mathrm{TCB}$ & 223 & $12.39 \pm 0.41$ & $0.922 \pm 0.003$ & $67.8 \pm 2.9$ & $7.74 \pm 0.36$ & 2.78 \\
\hline
\end{tabular}

${ }^{a}$ Hole mobility values of HTAZ, FTAZ, and 3'-FT-FTAZ blends were obtained from devices with PEDOT:PSS as hole transporting layers.

in a large hypsochromic shift of its absorption edge by $\sim 70 \mathrm{~nm}$, leading to an enlarged optical band gap of $2.23 \mathrm{eV}$ estimated from the onset of film absorption (Figure $2 b$ ). On the other hand, the almost perfectly planar conjugated backbones of these two $4^{\prime}$-FT polymers (4'-FT-HTAZ and $4^{\prime}$-FT-FTAZ), as shown in Figure 1, shift their absorption edges to longer wavelength by $\sim 40 \mathrm{~nm}$, narrowing their band gaps to $\sim 1.9 \mathrm{eV}$ (Figure 2b). Interestingly, while 3 '-FT-FTAZ demonstrates a further red-shift of its absorption in the solid state due to aggregation of conjugated polymers (Figure $2 \mathrm{~b}$ ), the individual UV-vis absorption spectrum of the other five polymers as thin films (Figure 2b) is almost identical to their individual UV-vis spectrum in solution (Figure $2 \mathrm{a}$ ). This implies that the other five polymers would have a strong tendency to aggregate even in the solution state. To verify this, we measured the temperature dependent on UV-vis absorption of each polymer solution (Figure S6). Indeed, the shoulder near the absorption edge of the solution UV-vis, indicative of the aggregated state of conjugated polymers, gradually disappears at elevated temperatures. However, the threshold temperature for the complete suppression of aggregation varies: at $30{ }^{\circ} \mathrm{C}$ for $3^{\prime}$-FTHTAZ, $50{ }^{\circ} \mathrm{C}$ for HTAZ, $\sim 100{ }^{\circ} \mathrm{C}$ for FTAZ, and $\sim 100{ }^{\circ} \mathrm{C}$ for $4^{\prime}$-FT-HTAZ. Strikingly, for $4^{\prime}$-FT-FTAZ, this absorption shoulder is still visible even at $110{ }^{\circ} \mathrm{C}$ (Figures S6). Since this threshold temperature is believed to indicate the strength of aggregation of conjugated polymers in solution, ${ }^{36,37}$ we can estimate the strength of aggregation for these six polymers as follows: $3^{\prime}$-FT-FTAZ $<3^{\prime}$-FT-HTAZ $<$ HTAZ $<$ FTAZ $\approx 4^{\prime}$ FT-HTAZ $<4^{\prime}$-FT-FTAZ. Apparently, the strong aggregation behavior of $4^{\prime}$-FT polymers and the weak aggregation behavior of $3^{\prime}$-FT polymers in solutions can be correlated with the large difference in the planarity of conjugated backbones between $3^{\prime}$ FT polymers and $4^{\prime}$-FT polymers (Figure 1).

We estimated the highest occupied molecular orbital (HOMO) energy levels for all six polymers with cyclic voltammetry $(\mathrm{CV})$. While the actual voltammograms are presented in Figure S7, these experimentally determined HOMO energy levels are summarized in Table 1 , together with the HOMO levels and the LUMO (i.e., lowest occupied molecular orbital) levels calculated via DFT. While there is a noticeable difference between the experimental result and the calculated one for the HOMO energy level for each polymercommonly observed for these conjugated polymers, the impact of fluorination on the HOMO level in this series of polymers has shown the similar trend for either calculated results or experimental ones. Specifically, adding two fluorine substituents to either the central TAZ unit (i.e., FTAZ) or to the $4^{\prime}$ positions of the two flanking thienyl units (i.e., $4^{\prime}$-FT-HTAZ) helps lower the HOMO level of fluorinated polymers by roughly the same amount $(\sim 0.1 \mathrm{eV})$. Furthermore, adding two more fluorine substituents to the $4^{\prime}$ positions of these two flanking thienyl units of FTAZ (i.e., 4'-FT-FTAZ) further deepens the HOMO level, whereas the lowest HOMO level of $3^{\prime}$-FT-FTAZ (isomer to $4^{\prime}$-FT-FTAZ) can be explained by the twisted conjugated backbone together with the four fluorine substituents.

2.4. Photovoltaic Properties. The photovoltaic properties of all six polymers were investigated in the bulk heterojunction $(\mathrm{BHJ})$ solar cells with a normal device configuration: indium doped tin oxide (ITO)/copper(I) thiocyanate $(\mathrm{CuSCN}) /$ polymer:phenyl- $\mathrm{C}_{61}$-butyric acid methyl ester $\left(\mathrm{PC}_{61} \mathrm{BM}\right) / \mathrm{Ca} /$ Al. The $J-V$ curves and external quantum efficiency (EQE) curves of optimized devices are presented in Figure $3 a$ and $3 b$, respectively, with the related device characteristics summarized in Table 2. Given the low HOMO levels of these polymers, we selected $\mathrm{CuSCN}$, which has high ionization potential (5.5 $\mathrm{eV}),{ }^{38}$ as the hole transporting layer (HTL) to form an Ohmic contact with the $\mathrm{BHJ}$ blend. We also attempted to optimize the processing conditions for different polymers, in particular, the solvent and additives, and the active layer thickness, in order to obtain the maximum device efficiency for each polymer based $\mathrm{BHJ}$ blend. It appears that chlorobenzene (CB) with $3 \%$ 
addictive 1,8-diiodooctane (DIO) offers the best device performance for $3^{\prime}$-FT-HTAZ and $3^{\prime}$-FT-FTAZ, while TCB seems to be the best choice of solvent for the other four polymers. For comparison, we also evaluated devices employing poly(3,4-ethylenedioxythiophene) polystyrenesulfonate (PEDOT:PSS) as the HTL, with the data summarized in Table S4. In fact, comparable device characteristics were achieved for HTAZ, FTAZ, and 3'-FT-HTAZ when switching from CuSCN to PEDOT:PSS, whereas lower device performance was observed for 3'-FT-FTAZ, 4'-FT-HTAZ, and 4'-FT-FTAZ with PEDOT:PSS as the HTL, mainly due to decreased $V_{\text {oc }}$ and FF values.

Short Circuit Current $\left(J_{s c}\right)$. The first observation is that $J_{s c}$ values of $\mathrm{BHJ}$ devices for these three difluorinated polymers (FTAZ, 3'-FT-HTAZ, and 4'-FT-HTAZ) are similar and noticeably higher than that of the nonfluorinated polymer (HTAZ) based BHJ device (Table 2). This clearly indicates that the fluorine can exert a similar beneficial impact on improving the $J_{\mathrm{sc}}$ even being on these more electron-rich thienyl units. Combining fluorinated thienyls with fluorinated TAZ, that is, 4'-FT-FTAZ, offers a negligible enhancement on the $J_{\text {sc }}$ of its $\mathrm{BHJ}$ device. This implies that excessive fluorination of the HTAZ polymer does not offer an additional boost to the $J_{\text {sc }}$ of its device, but it does not introduce negative influence to the $J_{s c}$ either. However, $3^{\prime}$-FT-FTAZ, the structural isomer to $4^{\prime}$-FT-FTAZ, only shows significantly reduced $J_{\text {sc }}$ with its device. This can be largely ascribed to the much-increased band gap of 3 -FT-FTAZ, because of its distorted conjugated backbone. Additionally, 3'-FT-FTAZ-based $\mathrm{BHJ}$ device also shows significantly lower EQE values in its spectrum (Figure 3b) than other polymers. This is not due to an insufficient exciton quenching, since the photoluminescence (PL) quenching efficiencies of the $\mathrm{BHJ}$ blends based on the four new polymers are all over $90 \%$ (Figure S9 and Table S3). Thus, the low EQE values in the case of 3 -FT-FTAZ is likely caused by other factors, for example, significant loss of charge carriers to various recombinational losses because of a low hole mobility.

Open Circuit Voltage $\left(V_{o c}\right)$. Though the position of two fluorine substituents on the HTAZ polymer (i.e., FTAZ, 3'-FTHTAZ, and $4^{\prime}$-FT-HTAZ) does not seem to affect the $J_{\text {sc }}$ values of $\mathrm{BHJ}$ devices, it has a strong impact on the $V_{\mathrm{oc}}$ values. For example, relocating the two fluorine substituents from the fluorinated TAZ unit to the $4^{\prime}$ position of the two flanking thienyl units (i.e., from FTAZ to $4^{\prime}$-FT-HTAZ) only offers marginal improvement of the $V_{\text {oc }}$ value (from 0.805 to 0.820 $\mathrm{V})$. However, the relocation of fluorine substituents to the $3^{\prime}$ position of the two flanking thienyl units (i.e., from FTAZ to $3^{\prime}$-FT-HTAZ) results in a significant boost of the $V_{\text {oc }}$ value to 0.909 V. Adding two more fluorine substituents onto the difluorinated polymers can further increase the $V_{\text {oc }}$ values, reaching $0.922 \mathrm{~V}$ for $4^{\prime}$-FT-FTAZ and $\sim 1 \mathrm{~V}$ for $3^{\prime}$-FT-FTAZ. In fact, the trend of $V_{\text {oc }}$ values matches well with that of HOMO levels of these six polymers (Table 1): for example, the lowest HOMO level of $3^{\prime}$-FT-FTAZ is translated into the highest $V_{\text {oc }}$ of the corresponding $\mathrm{BHJ}$ device. Nevertheless, given that the value of $V_{\text {oc }}$ is affected by other factors than just the HOMO level, we will discuss the $V_{\text {oc }}$ further in the following section.

Fill Factor (FF). One of the most unique features for FTAZ is the high FF $(\sim 70 \%)$ of its $\mathrm{BHJ}$ device even with an active layer as thick as $300 \mathrm{~nm} .{ }^{12}$ We are pleased to find that this desirable feature is maintained with the other two difluorinated polymers ( $3^{\prime}$-FT-HTAZ and $4^{\prime}$-FT-HTAZ) and the tetra-fluorinated $4^{\prime}$ -
FT-FTAZ, all of which show high values of FF $(\sim 70 \%)$ in their $\mathrm{BHJ}$ devices (Table 2; complete data sets at difference thickness in Tables S5 and S6). In our previous study, Li et al. discovered that the high FF of FTAZ was determined by its high hole mobility (on the order of $10^{-3} \mathrm{~cm}^{2} /(\mathrm{V} \cdot \mathrm{s})$ ). This high mobility enables a fast charge extraction to the electrodes, resulting in a low steady state charge carrier density and much reduced recombination. ${ }^{9}$ Given the structurally similarity of $3^{\prime}$-FTHTAZ, 4'-FT-HTAZ, and 4'-FT-FTAZ to that of FTAZ, we speculated that a high hole mobility would also be the reason for the observed high $\mathrm{FF}$ for these $\mathrm{BHJ}$ devices. This was confirmed by the measured hole mobilities for these polymers in their BHJ blends, which are all on the order of $10^{-3} \mathrm{~cm}^{2} /(\mathrm{V}$. s) at different thicknesses of the active layer (Figure 4). On the

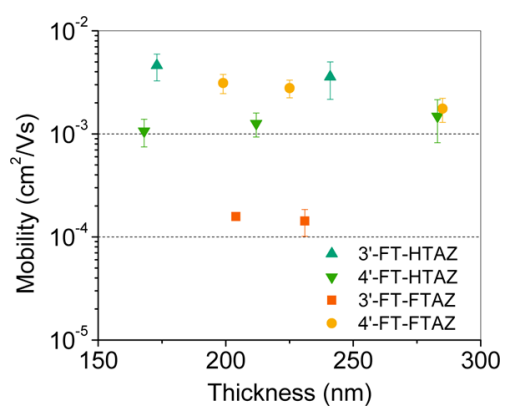

Figure 4. Hole mobilities at different thicknesses for the four novel polymer: $\mathrm{PC}_{61} \mathrm{BM}$ blends.

other hand, the low hole mobility of $3^{\prime}$-FT-FTAZ, which is on the order of $10^{-4} \mathrm{~cm}^{2} /(\mathrm{V} \cdot \mathrm{s})$, explains the noticeably lower FF of its BHJ device, similar to the case of HTAZ.

These results indicate that adding two fluorine substituents to the $4^{\prime}$ position on the two flanking thienyl units in the HTAZ polymer (i.e., 4'-FT-HTAZ) has almost identical impact on all device characteristics as adding two fluorine substituents to the central TAZ unit (i.e., FTAZ). Notably, substituting fluorine to the $3^{\prime}$ position on the two flanking thienyl units (i.e., $3^{\prime}$-FT-HTAZ) offers even higher device efficiency than that of FTAZ based device (7.4\% vs $6.6 \%$ ), primarily due to a much increased $V_{\text {oc }}(0.909 \mathrm{~V}$ vs $0.805 \mathrm{~V})$. With a slightly higher $V_{\text {oc }}$ and $J_{\text {sc }}$ of its BHJ device than those of $3^{\prime}$-FT-HTAZ based device, the tetra-fluorinated $4^{\prime}$-FT-FTAZ further improves the device efficiency to $7.7 \%$. In contrast, its isomer, $3^{\prime}$-FT-FTAZ, suffers from a low $J_{\text {sc }}$ value and FF and leads to the lowest device efficiency in those series of polymers.

2.5. CT States and Energy Loss Mechanisms. First proposed by Vandewal et al., it is generally accepted that $V_{\text {oc }}$ is primarily determined by the interfacial charge-transfer (CT) states between the donor and the acceptor materials rather than by the energy level difference between the HOMO of the donor material and LUMO level of the acceptor material. ${ }^{39}$ This relationship is quantitatively shown as eq $1 .^{39}$ To further understand the trend in $V_{\text {oc }}$ values in this series of polymers, we carried out high sensitivity EQE measurements and fitted the obtained spectra (Figure S10) using eq 2 to obtain the energy of the CT state $\left.\left(E_{\mathrm{CT}}\right)\right)^{39}$ Furthermore, we can estimate the loss due to nongeminate recombination $\left(\Delta E_{\mathrm{NG}}\right)$ via $\Delta E_{\mathrm{NG}}=E_{\mathrm{CT}}-$ $\mathrm{eV}_{\alpha}$, and the charge separation energy/exciton splitting energy $\left(\Delta E_{\mathrm{CS}}\right)$ via $\Delta E_{\mathrm{CS}}=E_{\mathrm{opt}}-E_{\mathrm{CT}}$, which is another significant loss mechanism. ${ }^{40}$ Table 3 summarizes all results from these calculations. 
Table 3. Energy of CT State of Polymer Solar Cells and $V_{\text {oc }}$ Loss

$\begin{array}{lcccccc}\text { polymer } & V_{\text {oc }}(\mathrm{V}) & E_{\text {opt }}{ }^{a}(\mathrm{ev}) & E_{\mathrm{CT}}(\mathrm{eV}) & E_{\mathrm{CT}}-\mathrm{eV}_{\mathrm{oc}}(\mathrm{eV}) & E_{\text {opt }}-E_{\mathrm{CT}}(\mathrm{eV}) & \text { total loss: } E_{\text {opt }}-\mathrm{eV} \text { oc }(\mathrm{eV}) \\ \text { HTAZ } & 0.74 & 1.66 & 1.36 & 0.62 & 0.30 & 0.92 \\ \text { FTAZ } & 0.80 & 1.66 & 1.42 & 0.62 & 0.12 & 0.86 \\ \text { 3'-FT-HTAZ } & 0.91 & 1.66 & 1.54 & 0.63 & 0.22 & 0.75 \\ \text { 4'-FT-HTAZ } & 0.82 & 1.66 & 1.44 & 0.62 & 0.06 & 0.84 \\ \text { 3'-FT-FTAZ } & 0.99 & 1.66 & 1.60 & 0.61 & 0.10 & 0.67 \\ \text { 4'-FT-FTAZ } & 0.92 & 1.66 & 1.56 & 0.64 & 0.74\end{array}$

${ }^{a} E_{\text {opt }}$ of $\mathrm{PC}_{61} \mathrm{BM}$ was used because it is the minimal $E_{\text {opt }}$ value in the $\mathrm{BHJ}$ blends.

$$
\begin{aligned}
V_{\mathrm{oc}} & =\frac{k T}{q} \ln \left(\frac{J_{\mathrm{ph}}}{J_{0}}+1\right) \\
& =\frac{E_{\mathrm{CT}}}{q}+\frac{k T}{q} \ln \left(\frac{J_{\mathrm{sc}} h^{3} c^{2}}{f q 2 \pi\left(E_{\mathrm{CT}}-\lambda\right)}\right)+\frac{k T}{q} \ln \left(\mathrm{EQE}_{\mathrm{EL}}\right) \\
\mathrm{EQE}_{\mathrm{PV}}(E) & =\frac{f}{E \sqrt{4 \pi \lambda k T}} \exp \left(\frac{-\left(E_{\mathrm{CT}}+\lambda-E\right)^{2}}{4 \lambda k T}\right)
\end{aligned}
$$

Indeed, the energy of the CT state $\left(E_{\mathrm{CT}}\right)$ linearly matches the $V_{\text {oc }}$ value, with the energy losses from $E_{\mathrm{CT}}$ to $\mathrm{e} V_{\mathrm{oc}}$ are similar $(\sim 0.62 \mathrm{eV})$ for all $\mathrm{BHJ}$ blends and fall into the range of 0.5 to $0.7 \mathrm{eV}$, typically observed for organic solar cells. ${ }^{41}$ This indicates that the energy losses due to nongeminate recombination are similar for all studied $\mathrm{BHJ}$ systems. Thus, the observed difference in the $V_{\text {oc }}$ values is from the difference in the required energy for exciton splitting in different $\mathrm{BHJ}$ systems $\left(\Delta E_{\mathrm{CS}}=E_{\mathrm{opt}}-E_{\mathrm{CT}}\right)$. While the driving force for the exciton splitting $\left(\Delta E_{\mathrm{CS}}\right)$ is around $0.25 \mathrm{eV}$ for HTAZ, FTAZ, and $4^{\prime}$-FT-FTAZ, we obtained very low driving forces to split excitons for $3^{\prime}$-FT-HTAZ and $4^{\prime}$-FT-FTAZ $(\sim 0.1 \mathrm{eV})$, and an even lower driving force for $3^{\prime}$-FT-FTAZ $(0.06 \mathrm{eV})$. Similar results (i.e., extremely low $\Delta \mathrm{E}_{\mathrm{CS}}$ yet highly efficient exciton splitting) have been recently reported in other systems ${ }^{42,43}$ as well; thus, it becomes increasingly clear that a high $\Delta E_{\mathrm{CS}}$ is not a prerequisite for efficient exciton splitting and charge generation.

2.6. Morphology. While some device characteristics of polymer solar cells can be largely correlated with the optical and electrochemical properties of the conjugated polymer employed in such a solar cell (e.g., $V_{\text {oc }}$ with the HOMO level), further understanding other characteristics, including mobility, $\mathrm{FF}$, and $J_{\mathrm{sc}}$ would require insights into the morphological features of such a bulk heterojunction blend. For example, in our previous studies, $\mathrm{Li}$ et al. showed that increasing the molecular weight $\left(M_{\mathrm{n}}\right)$ of FTAZ polymer from $10 \mathrm{~kg} / \mathrm{mol}$ to 40 $\mathrm{kg} / \mathrm{mol}$ could induce more "face-on" orientation of the conjugated backbone, leading to a higher hole mobility. ${ }^{30}$ Furthermore, FTAZ having a higher $M_{\mathrm{n}}(40 \mathrm{~kg} / \mathrm{mol})$ also showed a smaller domain size $(\sim 22 \mathrm{~nm})$ for the polymerenriched domains, benefiting the exciton dissociation and charge extraction. ${ }^{30}$ In this study, we continued to apply $2 \mathrm{D}$ grazing incidence wide-angle X-ray scattering (GIWAXS) and resonant soft X-ray scattering (R-SoXS) to investigate the morphology in $\mathrm{BHJ}$ blends and in the neat polymer films.

Overall, these four new fluorinated polymers demonstrate low crystallinity in their neat polymer films, indicated by the broad $(h 00)$ diffraction peaks in their 2D GIWAX patterns (Figures 5 and 6), a feature that has been also observed for analogous HTAZ and FTAZ. ${ }^{9}$ From the 2D GIWAXS patterns of neat polymer films shown in Figure $5 a-d$, the simultaneous appearance of out-of-plane (010) and in-plane (100) observed in pure $4^{\prime}$-FT polymers indicates that both $4^{\prime}$-FT-FTAZ and $4^{\prime}$ FT-HTAZ preferentially form crystallites adopting face-on orientation relative to the substrates. However, distinctive trends are found for 2D GIWAXS patterns of 3'-FT polymers, where both (100) and (010) peaks display out-of-plane preference. This suggests the formation of rolling-log crystallites, which adopt statistically random orientations with the backbone direction locked within the plane parallel to the substrate. ${ }^{44}$ Furthermore, the 1D GIWAXS profiles of polymer: $\mathrm{PC}_{61} \mathrm{BM}$ blends (Figure 6) show that the position of the $\mathrm{PC}_{61} \mathrm{BM}$ diffraction peaks $\left(q=1.35 \AA^{-1}\right)$ are similar for all blends, indicating that the fluorination on these flanking thienyl units does not change the aggregate size of $\mathrm{PC}_{61} \mathrm{BM}$ in $\mathrm{BHJ}$ blends. In addition, the orientation preference of polymers is maintained when blended with $\mathrm{PC}_{61} \mathrm{BM}$ (Figure 5). In fact, these features and results from 2D GIWAXS and the associated pole figures correlate strongly with the results presented earlier. For example, the orientation preference is closely related with the planarity of the polymer backbones. A planar conjugated backbone would promote the "face-on" orientation of the crystallites, as we have observed for these two $4^{\prime}$-FT polymers. A twisted backbone, on the other hand, would induce randomness in the orientation of the crystallites, as observed in the case of these two $3^{\prime}$-FT polymers, as well as FTAZ (Figure S11). Though orientation of crystallites of those polymers are different, compared to HTAZ (OF) which showed very weak $\pi-\pi$ stacking in blend with $\mathrm{PC}_{61} \mathrm{BM}^{9}$, the four fluorine-substituted polymers, 3'-FT-HTAZ, 3'-FT-FTAZ, 4'FT-HTAZ, and $4^{\prime}$-FT-FTAZ, show much enhanced $\pi-\pi$ stacking, indicated by the strong (010) peak in Figure $6 \mathrm{~d}$. This enhanced $\pi-\pi$ stacking helps form continuous intermolecular hole transport channel traversing the thick film. However, we speculate that the severe steric hindrance between the conjugated units of 3 -FT-FTAZ would lead to much reduced intramolecular hole transport and result in the observed low hole mobility of 3'-FT-FTAZ based BHJ blends.

We further estimated the crystallinity of the polymers. The coherence length of the $\pi-\pi$ stacking in the "face-on" crystallites of $4^{\prime}$-FT-FTAZ, estimated from the Scherrer's equation $^{45}$ (Figure S13), is $30 \AA$, which is noticeably larger than that of $4^{\prime}$-FT-HTAZ ( $20 \AA$ ), which probably contributes to the higher hole mobility.

As we and others have demonstrated, ${ }^{46-48}$ R-SoXS can provide overall compositional morphology including domain spacing, domain purity and orientation of polymer chains relative to $\mathrm{D} / \mathrm{A}$ interface. The morphological features of the respective $\mathrm{BHJ}$ blends of polymer: $\mathrm{PC}_{61} \mathrm{BM}$, probed by $\mathrm{R}-\mathrm{SoXS}$, are very similar for $3^{\prime}$-FT-HTAZ, $4^{\prime}$-FT-HTAZ and $4^{\prime}$-FTFTAZ based blends (Figure S14 and Table S9), and are not strongly related to the device performance (Table 2). This 

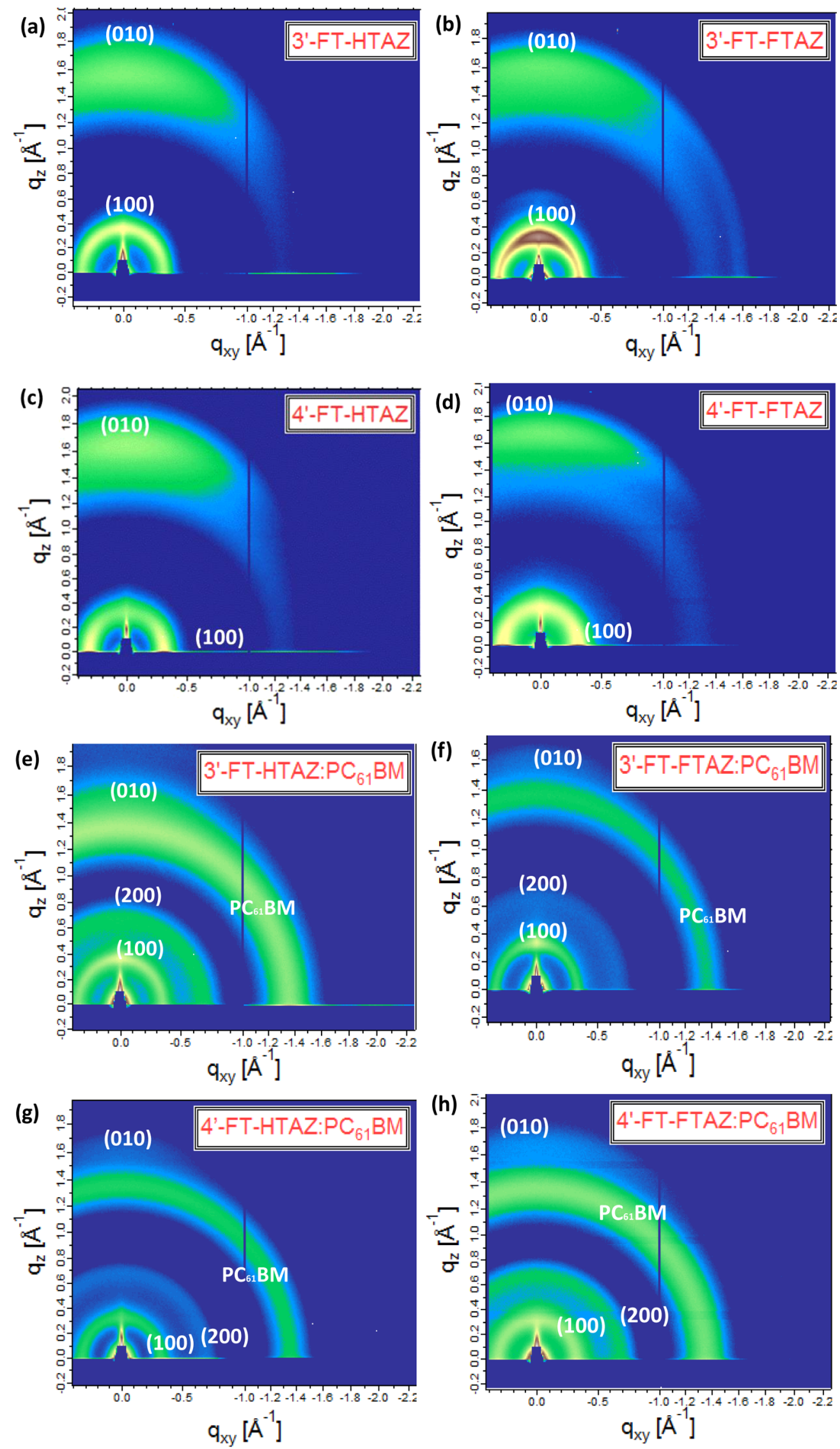

Figure 5. 2D GIWAXS patterns of $(\mathrm{a}-\mathrm{d})$ neat polymer films and $(\mathrm{e}-\mathrm{h})$ of polymer: $\mathrm{PC}_{61} \mathrm{BM}$ blends. 

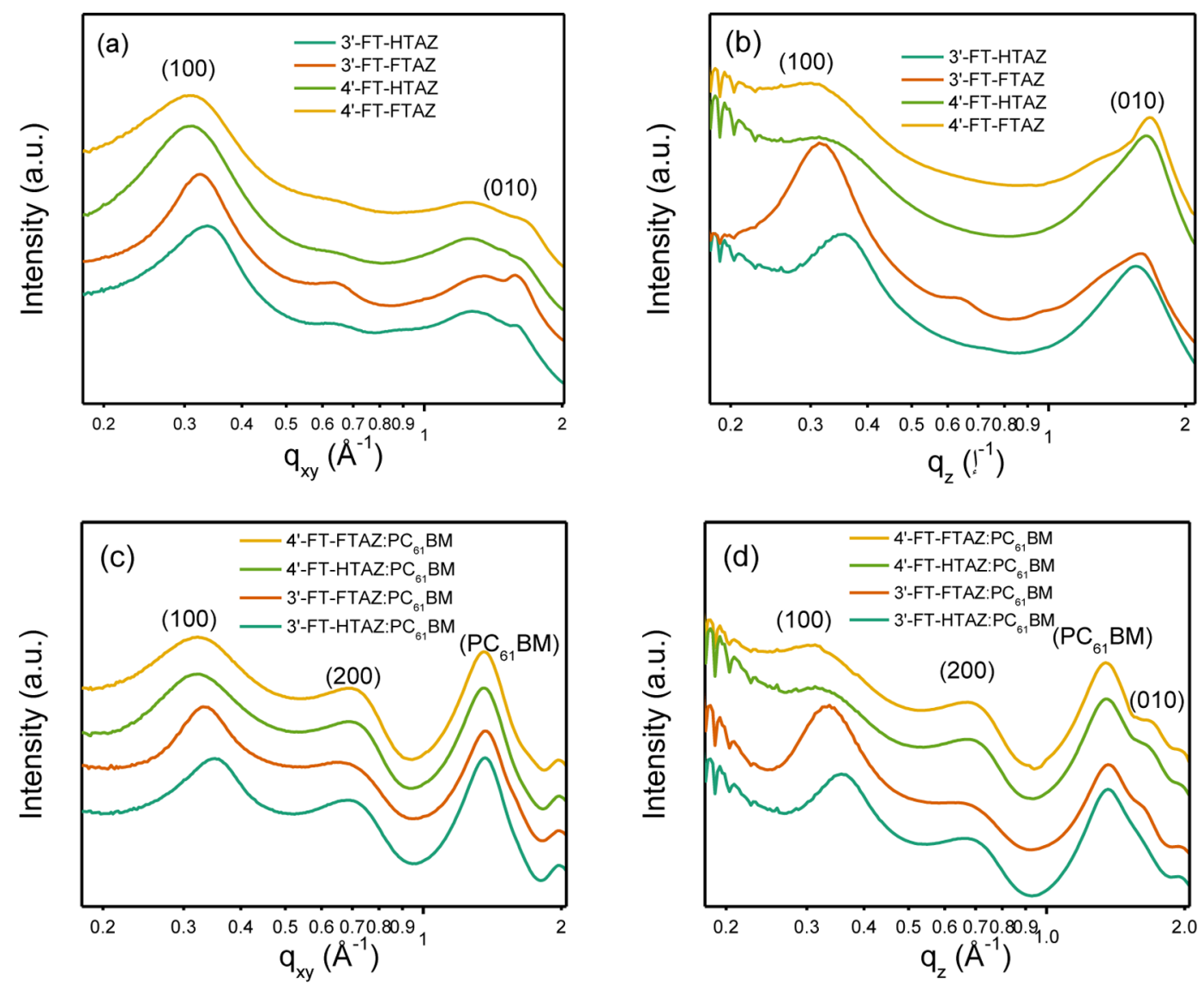

Figure 6. $1 \mathrm{D}$ profiles of neat polymer films along (a) $q_{x y}$ axis and (b) $q_{z}$ axis and of polymer: $\mathrm{PC}_{61} \mathrm{BM}$ blends (c) along $q_{x y}$ axis and (d) along $q_{z}$ axis.

finding is not particularly surprising, given that these four fluorinated polymers are structurally highly similar to the original FTAZ and HTAZ and no appreciable difference in morphological features for FTAZ and HTAZ was identified via R-SoXS. ${ }^{9}$

\section{CONCLUSION}

The most important finding in this study is that, the performance-enhancing " $F$ effect" can be well maintained when relocating these fluorine substituents from the electron deficient acceptor unit-benzotriazole in our case-to the electron rich thiophene units. This is supported by the fact that the $4^{\prime}$-FT-HTAZ polymer, as an isomer to the previously well-studied FTAZ polymer, offers almost identical device characteristics $\left(V_{\mathrm{oc}}, J_{\mathrm{sc}}, \mathrm{FF}\right.$, and mobility) to those of FTAZ based $\mathrm{BHJ}$ devices. Combining fluorinated thiophene units with the fluorinated acceptor unit, the tetra-fluorinated polymer, 4'FT-FTAZ, shows the highest device performance in this series of six structurally (closely) related polymers. The over $10 \%$ increase of device efficiency of $4^{\prime}$-FT-FTAZ when compared with FTAZ, is mainly because of the much improved $V_{\text {oc }}$ of $4^{\prime}$ FT-FTAZ based device $(0.92 \mathrm{~V}$, vs $0.80 \mathrm{~V}$ for FTAZ base device). This can be largely ascribed to the very low driving force for the exciton splitting in the case of $4^{\prime}$-FT-FTAZ $(\sim 0.1$ $\mathrm{eV}$ ), which reduces the loss from the band gap to $V_{\text {oc }}$ (i.e., small $V_{\text {oc }}$ loss).

Though the morphological features for these new fluorinated thiophene based polymers ( $3^{\prime}$-FT-HTAZ, 4'-FT-HTAZ, and $4^{\prime}$-FT-FTAZ) are largely similar (e.g., domain spacing and domain purity), the position of these fluorine substituents on these flanking thiophenes ( $3^{\prime}$ vs $\left.4^{\prime}\right)$ appears to have subtle impact on the molecular packing. For example, more "face-one" orientation of the conjugated backbone in the $\mathrm{BHJ}$ blend is observed for these two $4^{\prime}$-FT polymers, while a more "rolling log" like orientation is implied for these two $3^{\prime}$-FT polymers. Nevertheless, we want to emphasize that these are very minute differences, which do not seem to have a dramatic effect on key device characteristics ( $V_{\mathrm{oc}} J_{\mathrm{sc}} \mathrm{FF}$, and mobility).

In conclusion, we have discovered the performance enhancing effect of fluorine substitution on the linker thienyl unit with a series of PBnDT-TAZ polymers with varying number and position of fluorine substituents. Since many conjugated polymers with exceptional photovoltaic performance have a "donor-thiophene-acceptor-thiophene" pattern in their repeating units, it is very likely that incorporating these newly discovered monofluorinated thiophenes into their conjugated repeating units can boost the device efficiency even further.

\section{EXPERIMENTAL SECTION}

Device Fabrication. Glass substrates coated with patterned indium doped tin oxide (ITO) were purchased from Thin Film Devices, Inc. About $150 \mathrm{~nm}$ sputtered ITO pattern had a resistivity of $20 \Omega / \square$. Prior to use, the substrates were ultrasonicated in deionized water, acetone, and then 2-proponal for $15 \mathrm{~min}$ each. The substrates were dried under a stream of nitrogen gas and subjected to the treatment of UV-ozone for $15 \mathrm{~min}$. A filtered dispersion of PEDOT:PSS in water (Clevios PH500 from Heraeus) was then spun cast onto cleaned ITO substrates at $4000 \mathrm{rpm}$ for $60 \mathrm{~s}$ and then baked at $130{ }^{\circ} \mathrm{C}$ for $15 \mathrm{~min}$ in air to give a thin film with a thickness of about $40 \mathrm{~nm}$. For devices with CuSCN buffer layer, the CuSCN was 
dissolved in diethylsulfide with the concentration $22.7 \mathrm{mg} / \mathrm{mL}$ under stirring for $1 \mathrm{~h}$. Then the CuSCN solution was filtered by $0.2 \mu \mathrm{m}$ poly(tetrafluoroethylene) (PTFE) filter and spun-cast on the cleaned ITO substrates at $7000 \mathrm{rpm}$ for $60 \mathrm{~s}$ and then baked at $100{ }^{\circ} \mathrm{C}$ for 15 $\min$ in air to give a thin film with a thickness of about $40 \mathrm{~nm}$. For FTAZ, HTAZ, 4'-FT-FTAZ, and 4'-FT-HTAZ, blends of polymer:PC61BM $(1: 2 \mathrm{w} / \mathrm{w})$ were dissolved in 1,2,4-trichlorobenzene with heating at $130{ }^{\circ} \mathrm{C}$ for $6 \mathrm{~h}$. For $3^{\prime}$-FT-HTAZ and $3^{\prime}$-FT-FTAZ, blends of polymer:PC61BM $(1: 2 \mathrm{w} / \mathrm{w})$ were dissolved in chlorobenzene with 3 vol \% DIO with heating at $110{ }^{\circ} \mathrm{C}$ for $6 \mathrm{~h}$ and cooled to $80^{\circ} \mathrm{C}$ before spin coating. All the solutions were filtered through a $5.0 \mu \mathrm{m}$ PTFE filter and spun-cast at an optimized rpm for $60 \mathrm{~s}$ onto the PEDOT:PSS or CuSCN layer for conventional structure. For FTAZ, HTAZ, 4'-FT-FTAZ, 4'-FT-HTAZ, the substrates were transferred into vacuum chamber immediately after spin-coating and then dried at $30 \mathrm{mmHg}$ below atmosphere for $30 \mathrm{~min}$. For $3^{\prime}$-FTHTAZ and $3^{\prime}$-FT-FTAZ, the films were kept in covered Petri disk overnight after spin-coating. The devices were finished for measurement after thermal deposition of a $30 \mathrm{~nm}$ film of calcium and a $70 \mathrm{~nm}$ aluminum film as the cathode for a conventional structure at a base pressure of $2 \times 10^{-6} \mathrm{mbar}$. There are 8 devices per substrate, with an active area of $13 \mathrm{~mm}^{2}$ per device. Device characterization was carried out under AM $1.5 \mathrm{G}$ irradiation with the intensity of $100 \mathrm{~mW} / \mathrm{cm}^{2}$ (Oriel 91160, $300 \mathrm{~W}$ ) calibrated by an NREL certified standard silicon cell. Current density versus voltage $(J-V)$ curves were recorded with a Keithley 2400 digital source meter. EQE was detected under monochromatic illumination (OrielCornerstone $2601 / 4 \mathrm{~m}$ monochromator equipped with Oriel 70613NS QTH lamp), and the calibration of the incident light was performed with a monocrystalline silicon diode (Model No.: Newport 71580). All fabrication steps after adding the PEDOT:PSS or CuSCN layer onto ITO substrate, and characterizations were performed in gloveboxes under nitrogen atmosphere.

Grazing Incidence Wide Angle X-ray Scattering (GIWAXS). GIWAXS was measured at beamline 7.3.3 of Advanced Light Source (ALS) at Lawrence Berkeley National Laboratory. ${ }^{49}$ The $10 \mathrm{keV}$. X-ray beam was incident at a grazing angle of $0.13^{\circ}$, which maximized the scattering intensity from the samples and minimized the scattering intensity from the substrate. The scattered intensity was detected with a Dectris Pilatus $1 \mathrm{M}$ photon counting detector.

Resonant Soft X-ray Scattering (R-SoXS). R-SoXS was measured at beamline 11.0.1.2 of the $\mathrm{ALS}^{50}$ on blend films. Data were acquired at the photon energy of $283.6 \mathrm{eV}$ where the contrast between polymer and fullerene is relatively high enough for these materials, yet does not lead to beam damage or background fluorescence.

\section{ASSOCIATED CONTENT}

\section{S Supporting Information}

The Supporting Information is available free of charge on the ACS Publications website at DOI: 10.1021/acs.chemmater.7b01683.

General methods, experimental details, temperature dependent UV-vis spectra, GPC, cyclic voltammetry $(\mathrm{CV})$, additional photovoltaic properties, photoluminescence (PL), NMR, GIWAXS, and RSoXS (PDF)

\section{AUTHOR INFORMATION}

\section{Corresponding Author}

*E-mail: wyou@unc.edu.

\section{ORCID $\odot$}

Qianqian Zhang: 0000-0002-8896-1708

Franky So: 0000-0002-8310-677X

Wei You: 0000-0003-0354-1948

Notes

The authors declare no competing financial interest.

\section{ACKNOWLEDGMENTS}

Q.Z., J.R., and W.Y. were supported by the Office of Naval Research (Grant No. N000141410221), and a NSF grant (DMR-1507249). W.Y. and L.Y. were supported by a NSF grant (ECCS-1344745). GIWAXS/R-SoXS data acquisition and analysis by X.J., Z.P., and H.A. were supported by the ONR grant N000141512322. E.K. and F.S. acknowledge the support from the Office of Naval Research (N000141410173). X-ray data acquired at beamlines 11.0.1.2., 5.3.2.2, and 7.3.3. at the ALS in Berkeley National Lab, which was supported by the U.S. Department of Energy (DE-AC02-05CH11231). We thank Dr. Kezhao Du and Professor David Mitzi (Duke University) for single crystal X-ray characterization. We also want to thank Wesley Swords and Professor Gerald Meyer for assistance with PL measurements. In addition, we want to thank Prof. Xiaoniu Yang and Dr. Xiaoli Zhao (Changchun Institute of Applied Chemistry, Chinese Academy of Sciences) and Prof. David Haddleton and Sam Lawton (University of Warwick) for GPC measurements, and UNC Department of Chemistry Mass Spectrometry Core Laboratory for Mass Spectrometry measurement.

\section{REFERENCES}

(1) Zhou, H.; Yang, L.; You, W. Rational Design of High Performance Conjugated Polymers for Organic Solar Cells. Macromolecules 2012, 45, 607-632.

(2) Xiao, S.; Zhang, Q.; You, W. Molecular Engineering of Conjugated Polymers for Solar Cells: An Updated Report. Adv. Mater. 2017, 29, 1601391.

(3) Zhao, F.; Dai, S.; Wu, Y.; Zhang, Q.; Wang, J.; Jiang, L.; Ling, Q.; Wei, Z.; Ma, W.; You, W.; Wang, C.; Zhan, X. Single-Junction BinaryBlend Nonfullerene Polymer Solar Cells with $12.1 \%$ Efficiency. Adv. Mater. 2017, 29, 1700144.

(4) Li, M.; Gao, K.; Wan, X.; Zhang, Q.; Kan, B.; Xia, R.; Liu, F.; Yang, X.; Feng, H.; Ni, W.; Wang, Y.; Peng, J.; Zhang, H.; Liang, Z.; Yip, H.-L.; Peng, X.; Cao, Y.; Chen, Y. Solution-processed organic tandem solar cells with power conversion efficiencies $>12 \%$. Nat. Photonics 2017, 11, 85-90.

(5) Meyer, F. Fluorinated conjugated polymers in organic bulk heterojunction photovoltaic solar cells. Prog. Polym. Sci. 2015, 47, 7091.

(6) Albrecht, S.; Janietz, S.; Schindler, W.; Frisch, J.; Kurpiers, J.; Kniepert, J.; Inal, S.; Pingel, P.; Fostiropoulos, K.; Koch, N.; Neher, D. Fluorinated Copolymer PCPDTBT with Enhanced Open-Circuit Voltage and Reduced Recombination for Highly Efficient Polymer Solar Cells. J. Am. Chem. Soc. 2012, 134, 14932-14944.

(7) Blaskovits, J. T.; Bura, T.; Beaupré, S.; Lopez, S. A.; Roy, C.; de Goes Soares, J.; Oh, A.; Quinn, J.; Li, Y.; Aspuru-Guzik, A.; Leclerc, M. A Study of the Degree of Fluorination in Regioregular Poly(3hexylthiophene). Macromolecules 2017, 50, 162-174.

(8) Zhang, S.; Qin, Y.; Uddin, M. A.; Jang, B.; Zhao, W.; Liu, D.; Woo, H. Y.; Hou, J. A Fluorinated Polythiophene Derivative with Stabilized Backbone Conformation for Highly Efficient Fullerene and Non-Fullerene Polymer Solar Cells. Macromolecules 2016, 49, 29933000 .

(9) Li, W.; Albrecht, S.; Yang, L.; Roland, S.; Tumbleston, J. R.; McAfee, T.; Yan, L.; Kelly, M. A.; Ade, H.; Neher, D.; You, W. Mobility-Controlled Performance of Thick Solar Cells Based on Fluorinated Copolymers. J. Am. Chem. Soc. 2014, 136, 15566-15576.

(10) Zhou, H.; Yang, L.; Stuart, A. C.; Price, S. C.; Liu, S.; You, W. Development of Fluorinated Benzothiadiazole as a Structural Unit for a Polymer Solar Cell of 7\% Efficiency. Angew. Chem., Int. Ed. 2011, 50, 2995-2998.

(11) Bronstein, H.; Frost, J. M.; Hadipour, A.; Kim, Y.; Nielsen, C. B.; Ashraf, R. S.; Rand, B. P.; Watkins, S.; McCulloch, I. Effect of Fluorination on the Properties of a Donor-Acceptor Copolymer for 
Use in Photovoltaic Cells and Transistors. Chem. Mater. 2013, 25, 277-285.

(12) Price, S. C.; Stuart, A. C.; Yang, L.; Zhou, H.; You, W. Fluorine Substituted Conjugated Polymer of Medium Band Gap Yields 7\% Efficiency in Polymer-Fullerene Solar Cells. J. Am. Chem. Soc. 2011, 133, 4625-4631.

(13) Wang, Z.; Zhao, J.; Li, Y.; Peng, Q. Low band-gap copolymers derived from fluorinated isoindigo and dithienosilole: synthesis, properties and photovoltaic applications. Polym. Chem. 2014, 5, 4984-4992.

(14) Chen, H.-C.; Chen, Y.-H.; Liu, C.-C.; Chien, Y.-C.; Chou, S.-W.; Chou, P.-T. Prominent Short-Circuit Currents of Fluorinated Quinoxaline-Based Copolymer Solar Cells with a Power Conversion Efficiency of 8.0\%. Chem. Mater. 2012, 24, 4766-4772.

(15) Son, H. J.; Wang, W.; Xu, T.; Liang, Y.; Wu, Y.; Li, G.; Yu, L. Synthesis of Fluorinated Polythienothiophene-co-benzodithiophenes and Effect of Fluorination on the Photovoltaic Properties. J. Am. Chem. Soc. 2011, 133, 1885-1894.

(16) Carsten, B.; Szarko, J. M.; Son, H. J.; Wang, W.; Lu, L.; He, F.; Rolczynski, B. S.; Lou, S. J.; Chen, L. X.; Yu, L. Examining the Effect of the Dipole Moment on Charge Separation in Donor-Acceptor Polymers for Organic Photovoltaic Applications. J. Am. Chem. Soc. 2011, 133, 20468-20475.

(17) Zhang, M.; Guo, X.; Zhang, S.; Hou, J. Synergistic Effect of Fluorination on Molecular Energy Level Modulation in Highly Efficient Photovoltaic Polymers. Adv. Mater. 2014, 26, 1118-1123.

(18) Jo, J. W.; Jung, J. W.; Wang, H.-W.; Kim, P.; Russell, T. P.; Jo, W. H. Fluorination of Polythiophene Derivatives for High Performance Organic Photovoltaics. Chem. Mater. 2014, 26, 4214-4220.

(19) Li, Z.; Lin, H.; Jiang, K.; Carpenter, J.; Li, Y.; Liu, Y.; Hu, H.; Zhao, J.; Ma, W.; Ade, H.; Yan, H. Dramatic performance enhancement for large bandgap thick-film polymer solar cells introduced by a difluorinated donor unit. Nano Energy 2015, 15, $607-615$.

(20) Kawashima, K.; Fukuhara, T.; Suda, Y.; Suzuki, Y.; Koganezawa, T.; Yoshida, H.; Ohkita, H.; Osaka, I.; Takimiya, K. Implication of Fluorine Atom on Electronic Properties, Ordering Structures, and Photovoltaic Performance in Naphthobisthiadiazole-Based Semiconducting Polymers. J. Am. Chem. Soc. 2016, 138, 10265-10275.

(21) Zheng, Z.; Zhang, S.; Zhang, J.; Qin, Y.; Li, W.; Yu, R.; Wei, Z.; Hou, J. Over $11 \%$ Efficiency in Tandem Polymer Solar Cells Featured by a Low-Band-Gap Polymer with Fine-Tuned Properties. Adv. Mater. 2016, 28, 5133-5138.

(22) Min, J.; Zhang, Z.-G.; Zhang, S.; Zhang, M.; Zhang, J.; Li, Y. Synthesis and Photovoltaic Properties of D-A Copolymers Based on Dithienosilole and Benzotriazole. Macromolecules 2011, 44, 76327638.

(23) Duan, C.; Gao, K.; van Franeker, J. J.; Liu, F.; Wienk, M. M.; Janssen, R. A. J. Toward Practical Useful Polymers for Highly Efficient Solar Cells via a Random Copolymer Approach. J. Am. Chem. Soc. 2016, 138, 10782-10785.

(24) Fei, Z.; Shahid, M.; Yaacobi-Gross, N.; Rossbauer, S.; Zhong, H.; Watkins, S. E.; Anthopoulos, T. D.; Heeney, M. Thiophene fluorination to enhance photovoltaic performance in low band gap donor-acceptor polymers. Chem. Commun. 2012, 48, 11130-11132.

(25) Collado-Fregoso, E.; Boufflet, P.; Fei, Z.; Gann, E.; Ashraf, S.; Li, Z.; McNeill, C. R.; Durrant, J. R.; Heeney, M. Increased Exciton Dipole Moment Translates into Charge-Transfer Excitons in Thiophene-Fluorinated Low-Bandgap Polymers for Organic Photovoltaic Applications. Chem. Mater. 2015, 27, 7934-7944.

(26) Liu, S.; Kan, Z.; Thomas, S.; Cruciani, F.; Brédas, J.-L.; Beaujuge, P. M. Thieno[3,4-c]pyrrole-4,6-dione-3,4-difluorothiophene Polymer Acceptors for Efficient All-Polymer Bulk Heterojunction Solar Cells. Angew. Chem., Int. Ed. 2016, 55, 12996-13000.

(27) Kelly, M. A.; Roland, S.; Zhang, Q.; Lee, Y.; Kabius, B.; Wang, Q.; Gomez, E. D.; Neher, D.; You, W. Incorporating Fluorine Substitution into Conjugated Polymers for Solar Cells: Three Different Means, Same Results. J. Phys. Chem. C 2017, 121, 20592068.
(28) Sakamoto, Y.; Komatsu, S.; Suzuki, T. Tetradecafluorosexithiophene: The First Perfluorinated Oligothiophene. J. Am. Chem. Soc. 2001, 123, 4643-4644.

(29) Gilchrist, T. L. Ring-Opening of Five-Membered Heteroarmatic Anions. Adv. Heterocycl. Chem. 1987, 41, 41-74.

(30) Li, W.; Yang, L.; Tumbleston, J. R.; Yan, L.; Ade, H.; You, W. Controlling Molecular Weight of a High Efficiency Donor-Acceptor Conjugated Polymer and Understanding Its Significant Impact on Photovoltaic Properties. Adv. Mater. 2014, 26, 4456-4462.

(31) Bao, Z.; Chan, W. K.; Yu, L. Exploration of the Stille Coupling Reaction for the Synthesis of Functional Polymers. J. Am. Chem. Soc. 1995, 117, 12426-12435.

(32) Becke, A. D. Density-functional thermochemistry. III. The role of exact exchange. J. Chem. Phys. 1993, 98, 5648-5652.

(33) Lee, C.; Yang, W.; Parr, R. G. Development of the Colle-Salvetti correlation-energy formula into a functional of the electron density. Phys. Rev. B: Condens. Matter Mater. Phys. 1988, 37, 785-789.

(34) Ditchfield, R.; Hehre, W. J.; Pople, J. A. Self-Consistent Molecular-Orbital Methods. IX. An Extended Gaussian-Type Basis for Molecular-Orbital Studies of Organic Molecules. J. Chem. Phys. 1971, 54, 724-728.

(35) Jackson, N. E.; Savoie, B. M.; Kohlstedt, K. L.; Olvera de la Cruz, M.; Schatz, G. C.; Chen, L. X.; Ratner, M. A. Controlling Conformations of Conjugated Polymers and Small Molecules: The Role of Nonbonding Interactions. J. Am. Chem. Soc. 2013, 135, 10475-10483.

(36) Liu, Y.; Zhao, J.; Li, Z.; Mu, C.; Ma, W.; Hu, H.; Jiang, K.; Lin, H.; Ade, H.; Yan, H. Aggregation and morphology control enables multiple cases of high-efficiency polymer solar cells. Nat. Commun. 2014, 5, 5293.

(37) Wolf, J.; Cruciani, F.; El Labban, A.; Beaujuge, P. M. Wide Band-Gap 3,4-Difluorothiophene-Based Polymer with 7\% Solar Cell Efficiency: An Alternative to P3HT. Chem. Mater. 2015, 27, 41844187.

(38) Pattanasattayavong, P.; Yaacobi-Gross, N.; Zhao, K.; Ndjawa, G. O. N.; Li, J.; Yan, F.; O’Regan, B. C.; Amassian, A.; Anthopoulos, T. D. Hole-Transporting Transistors and Circuits Based on the Transparent Inorganic Semiconductor Copper(I) Thiocyanate (CuSCN) Processed from Solution at Room Temperature. Adv. Mater. 2013, 25, 1504-1509.

(39) Vandewal, K.; Tvingstedt, K.; Gadisa, A.; Inganäs, O.; Manca, J. $\mathrm{V}$. Relating the open-circuit voltage to interface molecular properties of donor:acceptor bulk heterojunction solar cells. Phys. Rev. B: Condens. Matter Mater. Phys. 2010, 81, 125204.

(40) Faist, M. A.; Kirchartz, T.; Gong, W.; Ashraf, R. S.; McCulloch, I.; de Mello, J. C.; Ekins-Daukes, N. J.; Bradley, D. D. C.; Nelson, J. Competition between the Charge Transfer State and the Singlet States of Donor or Acceptor Limiting the Efficiency in Polymer:Fullerene Solar Cells. J. Am. Chem. Soc. 2012, 134, 685-692.

(41) Burke, T. M.; Sweetnam, S.; Vandewal, K.; McGehee, M. D. Beyond Langevin Recombination: How Equilibrium Between Free Carriers and Charge Transfer States Determines the Open-Circuit Voltage of Organic Solar Cells. Adv. Energy Mater. 2015, 5, 1500123.

(42) Liu, J.; Chen, S.; Qian, D.; Gautam, B.; Yang, G.; Zhao, J.; Bergqvist, J.; Zhang, F.; Ma, W.; Ade, H.; Inganäs, O.; Gundogdu, K.; Gao, F.; Yan, H. Fast charge separation in a non-fullerene organic solar cell with a small driving force. Nat. Energy 2016, 1, 16089.

(43) Bauer, N.; Zhang, Q.; Zhao, J.; Ye, L.; Kim, J.-H.; Constantinou, I.; Yan, L.; So, F.; Ade, H.; Yan, H.; You, W. Comparing non-fullerene acceptors with fullerene in polymer solar cells: a case study with FTAZ and PyCNTAZ. J. Mater. Chem. A 2017, 5, 4886-4893.

(44) Ye, L.; Jiao, X.; Zhou, M.; Zhang, S.; Yao, H.; Zhao, W.; Xia, A.; Ade, H.; Hou, J. Manipulating Aggregation and Molecular Orientation in All-Polymer Photovoltaic Cells. Adv. Mater. 2015, 27, 6046-6054.

(45) Smilgies, D.-M. Scherrer grain-size analysis adapted to grazingincidence scattering with area detectors. J. Appl. Crystallogr. 2009, 42, $1030-1034$.

(46) Tumbleston, J. R.; Stuart, A. C.; Gann, E.; You, W.; Ade, H. Fluorinated Polymer Yields High Organic Solar Cell Performance for a 
Wide Range of Morphologies. Adv. Funct. Mater. 2013, 23, 34633470.

(47) Rivnay, J.; Mannsfeld, S. C. B.; Miller, C. E.; Salleo, A.; Toney, M. F. Quantitative Determination of Organic Semiconductor Microstructure from the Molecular to Device Scale. Chem. Rev. 2012, 112, 5488-5519.

(48) Tumbleston, J. R.; Collins, B. A.; Yang, L.; Stuart, A. C.; Gann, E.; Ma, W.; You, W.; Ade, H. The influence of molecular orientation on organic bulk heterojunction solar cells. Nat. Photonics 2014, 8, 385-391.

(49) Hexemer, A.; Bras, W.; Glossinger, J.; Schaible, E.; Gann, E.; Kirian, R.; MacDowell, A.; Church, M.; Rude, B.; Padmore, H. A SAXS/WAXS/GISAXS Beamline with Multilayer Monochromator. J. Phys.: Conf. Ser. 2010, 247, 012007.

(50) Gann, E.; Young, A. T.; Collins, B. A.; Yan, H.; Nasiatka, J.; Padmore, H. A.; Ade, H.; Hexemer, A.; Wang, C. Soft x-ray scattering facility at the Advanced Light Source with real-time data processing and analysis. Rev. Sci. Instrum. 2012, 83, 045110. 